\title{
Provision of Surgical Care for Children Across Somaliland: Challenges and Policy Guidance
}

\author{
Tessa L. Concepcion ${ }^{1} \cdot$ Emily R. Smith $^{1,2} \cdot$ Mubarak Mohamed $^{3} \cdot$ Shugri Dahir $^{3}$. \\ Edna Adan Ismail ${ }^{3} \cdot$ Andrew J. M. Leather ${ }^{4} \cdot$ Dan Poenaru $^{5} \cdot$ Henry E. Rice $^{1}$ on behalf of \\ the Global Initiative for Children's Surgery
}

Published online: 11 July 2019

(C) Société Internationale de Chirurgie 2019

\begin{abstract}
Background Existing data suggest a large burden of surgical conditions in low- and middle-income countries (LMICs). However, surgical care for children in LMICs remains poorly understood. Our goal was to define the hospital infrastructure, workforce, and delivery of surgical care for children across Somaliland and provide policy guidance to improve care.

Methods We used two established hospital assessment tools to assess infrastructure, workforce, and capacity at all hospitals providing surgical care for children across Somaliland. We collected data on all surgical procedures performed in children in Somaliland between August 2016 and July 2017 using operative logbooks.

Results Data were collected from 15 hospitals, including eight government, five for-profit, and two not-for-profit hospitals. Children represented $15.9 \%$ of all admitted patients, and pediatric surgical interventions comprised $8.8 \%$ of total operations. There were 0.6 surgical providers and 1.2 anesthesia providers per 100,000 population. A total of 1255 surgical procedures were performed in children in all hospitals in Somaliland over 1 year, at a rate of 62.4 surgical procedures annually per 100,000 children. Care was concentrated at private hospitals within urban areas, with a limited number of procedures for many high-burden pediatric surgical conditions.

Conclusions We found a profound lack of surgical capacity for children in Somaliland. Hospital-level surgical infrastructure, workforce, and care delivery reflects a severely resource-constrained health system. Targeted policy to improved essential surgical care at local, regional, and national levels is essential to improve the health of children in Somaliland.
\end{abstract}

Electronic supplementary material The online version of this article (https://doi.org/10.1007/s00268-019-05079-8) contains supplementary material, which is available to authorized users.

Emily R. Smith

Emily_R_Smith@baylor.edu

1 Duke Global Health Institute, Duke University, Durham, NC, USA

2 Department of Public Health, Baylor University, Waco, TX 76706, USA

\section{Introduction}

Although the global health agenda increasingly recognizes the importance of surgical care in low- and middle-income countries (LMICs) [1-3], surgical care delivery for

3 Edna Adan University Hospital, Hargeisa, Somaliland

4 King's Centre for Global Health and Health Partnerships, King's College London, London, UK

5 McGill University, Montreal, QC, Canada 
children remains poorly understood. Existing data suggest a large burden of surgical conditions in children in many LMICs [4-7]. Although precise data on the burden of surgical conditions in children in LMICs are limited, existing data suggest that the global burden of surgical disease in children is high, with congenital anomalies and injuries in children comprising a large proportion of the overall disease burden [4, 8-12]. However, detailed data on the delivery of surgical care for children remain limited due to lack of high-quality data, reliance on small cohort studies, and focus on urban areas [5, 6, 10, 13-18]. Additionally, studies which focus on government health facilities often underreport the large portion of surgical care which is provided at private facilities in many LMICs [10, 13, 19-22].

Somaliland faces many challenges as it rebuilds its healthcare system following long-standing civil conflicts and is the fourth poorest country in the world [23]. Using a national community-based survey, our group recently revealed a high prevalence of surgical conditions in children across the country (12.2\%), translating to approximately 256,000 children nationally who require surgical care [24]. The goal of our current study is to assess hospital-level infrastructure, human resources, and delivery of surgical care for children across Somaliland. To examine hospital infrastructure, we used two standardized assessment tools to define each institution's capacity, workforce, and surgical caseload. To measure the delivery of surgical care, we surveyed case logs from all hospitals across Somaliland and summarized data on pediatric surgical procedures. In conjunction with our previous burden of disease analysis [24], we used this information to develop several policy recommendations to improve surgical care for children in Somaliland.

\section{Material and methods}

\section{Setting}

Our study took place in Somaliland, a country in the Horn of Africa which-although not recognized as an independent state-has achieved relative stability and operated an autonomous government since separation from Somalia in 1991 [25]. The country had a gross domestic product (GDP) per capita of \$348 USD in 2015 [26], classifying it as the fourth poorest in the world by the World Bank [23]. Infant and under-5 mortality rates are among the highest in the world [27, 28] at 109 and 180 per 100,000 respectively [29].

In 1990, nearly all hospitals, clinics, and health posts were damaged or destroyed during the Somali civil war [30]. Since then, the country has struggled to rebuild its health system, with approximately $3 \%$ of its national budget of 160 million USD (in 2011) currently allocated to the health sector $[19,30]$. The public health system is comprised of primary health units, health centers, referral health centers, regional hospitals, and one national referral hospital [30]. Specialty hospitals include seven tuberculosis hospitals, one female fistula hospital, and one mental health hospital [30]. Although the public health sector is rebuilding following recent civil conflict, an estimated $60 \%$ of health services are provided through the private sector, which consists of non-government organizations, private health practitioners, clinics and hospitals, and traditional practitioners [30].

\section{Participants}

Hospitals were included in this study if they had the capacity to perform surgery, which was defined as the presence of at least one operating room. Although there is no national registry of public and private hospitals in the country, a total of 16 hospitals with surgical capacity for children across the country were identified based on information from local collaborators and conversations with Ministry of Health officials. Hospitals which had no surgical capacity were excluded. One private hospital, International Hospital in Hargeisa, chose not to participate in this study and was also excluded. Hospitals that performed surgical procedures on adults but had not performed procedures on children in the past 1 year were still included in hospital capacity analysis in order to understand the potential surgical capacity across these hospitals (Fig. 1).

\section{Hospital infrastructure, workforce, and capacity survey}

We combined the World Health Organization's (WHO) Surgical Assessment Tool - Hospital Walkthrough [31] and the Global Initiative for Children's Surgery's (GICS') Global Assessment in Pediatric Surgery (GAPS) [32] to create a single-page hospital assessment tool to assess surgical infrastructure and capacity (Supplementary File). Surveys were completed by either the lead surgeon or administrator at each hospital. The survey included data on hospital infrastructure, workforce, service delivery, financial indicators, and payment methods for patients [33]. To account for the reality that the same providers work at multiple hospitals [34, 35], on-site coordinators compiled a list of surgical and anesthesia providers and providers who were associated with their primary hospital of work. We chose not to have an external definition of provider, as providers in Somaliland often have different levels and years of training, and the locally reported classification more accurately represents the level of care they provide. 


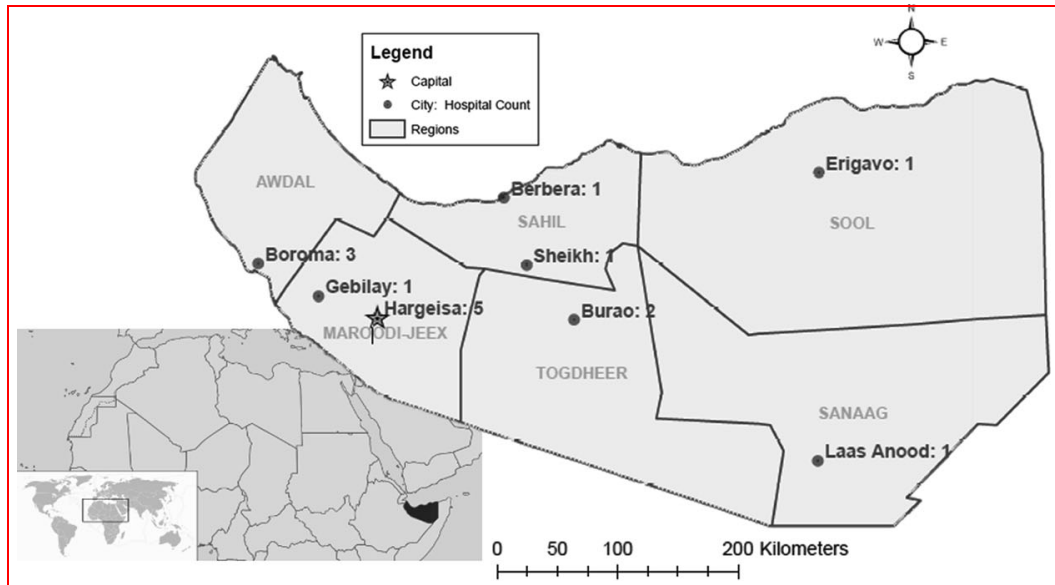

16 hospitals with surgical capacity

Fig. 1 Map and flowchart of hospitals included in study

\section{Surgical records data collection}

To assess the delivery of surgical care for children, we reviewed all hospital-based surgical records from surgical logbooks for all procedures on children ages 0 to 15 years who underwent surgical care between August 1, 2016, and July 31, 2017. Non-surgical inpatient medical records and surgical outpatient records were not included. We collected data on patient age, gender, surgical diagnosis: surgical procedure(s) performed, and date of surgery. As data were collected only from surgical logbooks, it did not include admission information, comorbidities, complications, or outcome.

\section{Data analysis}

Responses to the hospital capacity assessment were aggregated using Microsoft Excel (Microsoft Corp, Redmond, WA). Surgical diagnoses were coded by both a research assistant and a research manager, with diagnostic codes reviewed and classified into nine surgical specialties by a pediatric surgeon. Of the 15 hospitals included in the analysis, 11 hospitals had complete records available for 12 months, while four hospitals had between 1 and 8 months of data. Missing data for the child's age, gender, town of origin, type of anesthesia, surgical provider, and anesthesia provided were accounted for through multiple imputations using multivariate normal distribution using the SAS Markov Chain Monte Carlo computation. Data were summarized using frequency tables and median values with associated interquartile ranges (IQR). Child demographics, surgical procedure categories, and surgical diagnoses were stratified by hospital as well as by region and hospital type (private for-profit, not-for-profit, or government). Surgical indicators that are not child specific are reported "per 100,000 population" and surgical indicators that are child specific are reported "per 100,000 children". $p$ values were determined using the MantelHaenszel Chi-square test statistic. Data were analyzed in SAS 9.4 (SAS, Cary, NC) and Microsoft Excel 2010 (Microsoft Corp, Redmond, WA).

\section{Ethical considerations}

Institutional review board (IRB) approval was granted from Duke University. Since Somaliland does not have a national IRB, a letter of approval for the study was obtained from the Somaliland Ministry of Health.

\section{Results}

A total of 1255 surgical procedures were performed in children over 1 year at all 15 hospitals in Somaliland. There were 0.6 surgical providers and 1.2 anesthesia providers per 100,000 population, and hospital characteristics and surgical provision varied greatly between hospitals and regions.

\section{Hospital characteristics}

Of the 15 hospitals included in this analysis, eight are government, five private for-profit, and two private not-forprofit hospitals. Of the eight government hospitals, one is a national referral hospital (Hargeisa Group Hospital), six are regional hospitals, and one is a district hospital (Fig. 2). Overall, children made up $15.9 \%$ of all patients admitted monthly. All hospitals reported having electricity, running water, internet, phone service more than $75 \%$ of the time, 


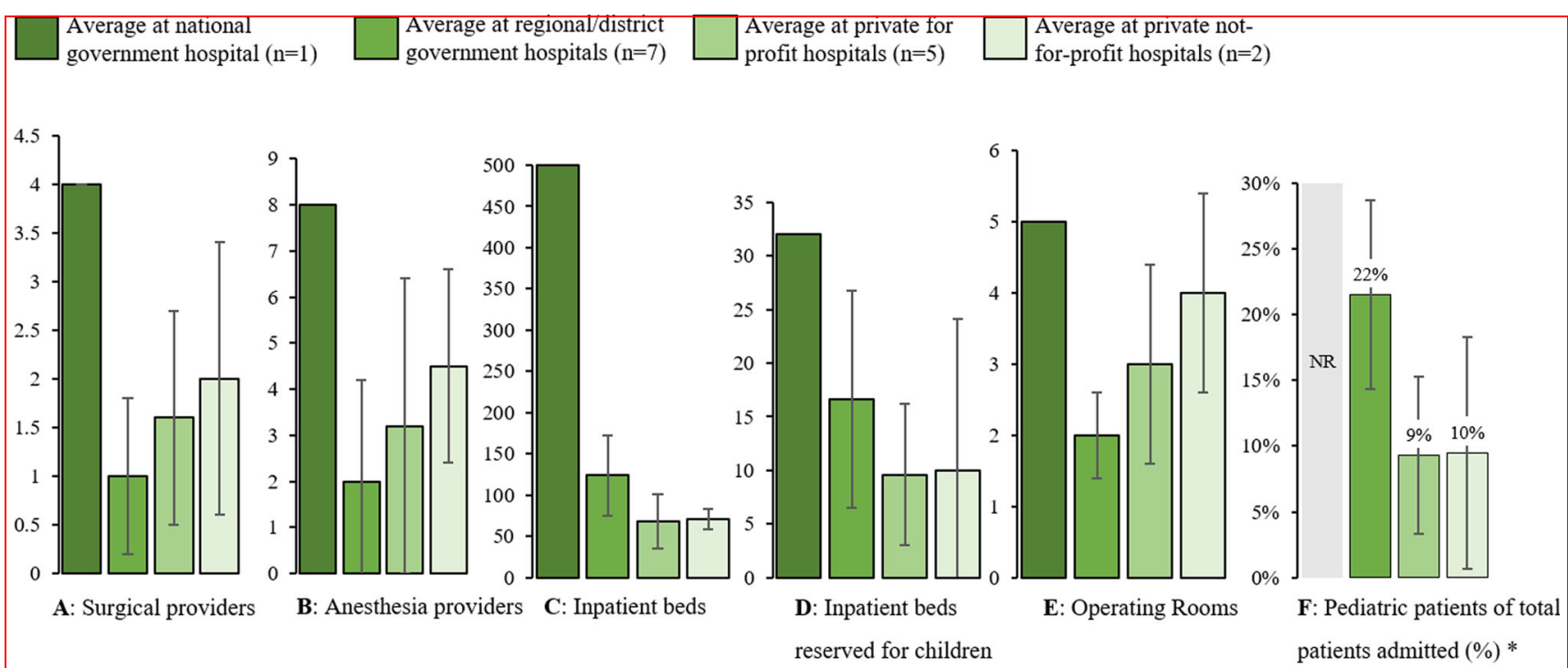

TOTAL AT ALL HOSPITALS WITHIN GROUP

\begin{tabular}{|l|l|l|l|l|l} 
& A & B & C & D & E \\
\hline National government & 4 & 8 & 500 & 32 & 5 \\
\hline Regional/district government & 7 & 14 & 866 & 116 & 14 \\
\hline Private for profit & 8 & 16 & 342 & 48 & 15 \\
\hline Private not-for-profit & 4 & 9 & 142 & 20 & 8 \\
\hline
\end{tabular}

* Pediatric inpatients per month / total number of inpatients per month $\mathrm{NR}=$ Not reported

Fig. 2 Surgical infrastructure by hospital type at 15 hospitals in Somaliland

while oxygen was available more than $50 \%$ of the time (Supplementary File). Number of beds ranged from 30-500 with an average of 123.3 beds per hospital (Supplementary File). The surgical workforce had a total number of 23 surgical ( 1 pediatric surgeon) and 47 anesthesia providers across the country, translating to a workforce density of 0.6 and 1.2 (per 100,000 population) (Fig. 3). Over half of all the surgical and anesthesia providers were located at hospitals in Maroodi Jeex. There were a total of 42 operating rooms across all hospitals in Somaliland, with hospitals in Maroodi Jeex having the highest number per hospital (3.8). (Fig. 3).

\section{Types of surgical procedures}

Over half of all procedures were performed on children over 5 years old $(52.8 \%)$ and only $0.2 \%$ of procedures were performed by a pediatric surgeon. We classified the 1255 surgical procedures, general surgery (22.9\%), otolaryngology (19.4\%), orthopedic surgery (15.8\%), ophthalmology $(15.1 \%)$, and neurosurgery (11.3\%). Slightly over half of the procedures were elective (58.6\%). Of all surgical procedures reported, the most common were tonsillectomy (18.3\%), various procedures for traumatic injury (11.2\%), and shunting for hydrocephalus $(7.5 \%)$ (Table 1). There were large variations in the ratio between elective/emergency procedures between regions, with more urban regions having elective cases while more rural regions having more emergent cases (Table 2). There was also a difference between age-groups and urgency ratios ( $p<0.003$ ), with children $0-28$ days and 1-12 months old receiving primarily emergency procedures $(60.7 \%$ and $67.5 \%$, respectively) rather than elective procedures (Fig. 4).

The most common procedure within each surgical specialty category was trauma in general surgery (19.9\%), tonsillitis in otolaryngology (94.7\%), fracture within orthopedics $(40.1 \%)$, cataract within ophthalmology (44.4\%), hydrocephalus within neurology (66.2\%), cleft lip within plastic surgery (46.4\%), circumcision within urology $(41.1 \%)$, and prolonged labor in obstetrics $(100 \%)$ (Table 3). Of the 1255 procedures in children, $80 \%$ were performed at private hospitals (private for-profit $28.3 \%$, private not-for-profit $51.5 \%$ ) and only $20 \%$ at public hospitals. (Table 4). There were differences in age-groups receiving surgery $(p<0.001)$ between hospital types, with over half of children at not-for-profit hospitals being 5 years or younger (53.0\%), while for-profit and public hospitals had less than half of children in this age group (44.8\% and $35.9 \%$ respectively). There was also a significant difference between hospital types in the emergency/elective ratio $(p<0.001)$ with private for-profit and private not-for-profit hospitals performing mostly elective surgeries $(72.8 \%$ and $61.7 \%$ respectively), while public 


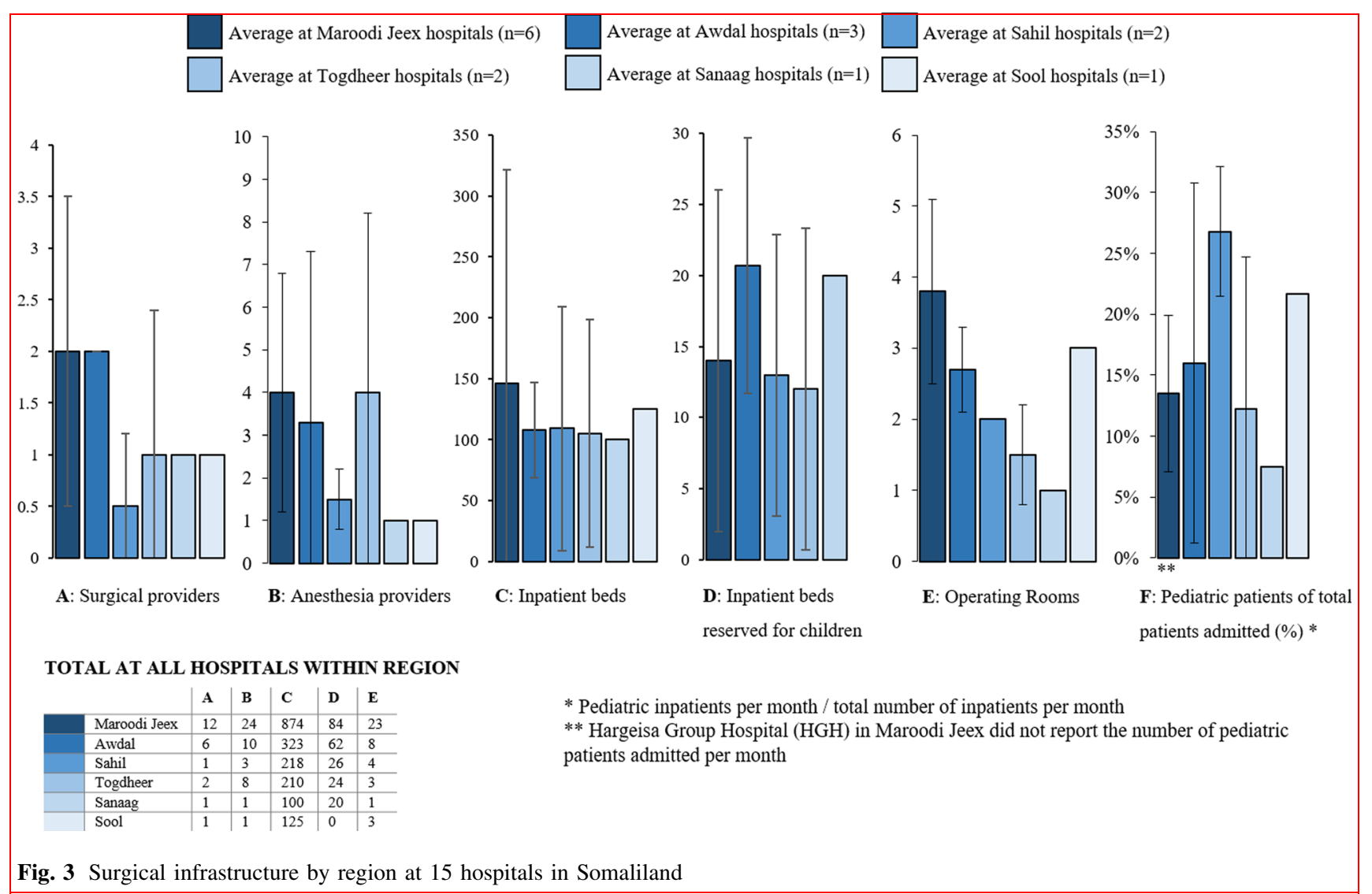

hospitals performed more emergency cases (68.0\%) (Table 4).

\section{Discussion}

As Somaliland rebuilds its healthcare system following civil conflict, there is a profound lack of surgical capacity for children. Through use of a national hospital-based survey, we found that only 1255 pediatric surgical procedures were performed over 1 year in Somaliland, translating to a rate of 62.4 surgical procedures per 100,000 children annually. Although the optimal rate of pediatric surgical procedures for children in LMICs has not been defined, this rate of surgical procedures is far below the minimum recommended operative volume of 5000 surgical procedures per 100,000 population for adults as identified by the Lancet Commission on Global Surgery (LCoGS) [36]. Additionally, the surgical workforce levels are strikingly low, at 1.8 surgical and anesthesia providers per 100,000 population (23 surgical providers, of which 1 is a pediatric surgeon, 47 anesthesia providers). Although this number does not include obstetric providers, it is far below the recommended level of 20 surgical, anesthesia, and obstetric (SAO) providers per 100,000 population as recommended by the LCoGS for adult surgical care [36]. Our analysis allows for several policy recommendations to improve the health of children in Somaliland and offers guidance that may be generalizable to other LMICs with similarly constrained resources in their national health systems.

As Somaliland rebuilds its public health sector, the scale-up of surgical capacity in Somaliland is challenging, given not only limited internal financial resources but also the absence of recognition by external multilateral aid agencies such as WHO [37]. Somaliland continues to face challenges in receiving aid due to lack of international recognition as an independent state. To address the gaps in surgical care for children in Somaliland, implementation of several health financing reforms will likely be required. In 2013, Somaliland passed the Draft Health Act of 2013 which aims to build a national health system that governs both public and private health services. In addition, the country has a National Health Policy and a National Development Policy, but does not have a formal insurance policy for health care. It is also important to understand the current financing mechanisms of Somaliland hospitals, both public and private. From a policy standpoint, incorporating children's surgical care as part of universal health coverage (UHC) is critical to improve their health [38]. Other African countries have reduced user fees for basic health care over recent years and replaced them with 
Table 1 Demographics children receiving surgical procedures $(N=1255)$

\begin{tabular}{|c|c|c|c|c|c|c|c|}
\hline No. of pediatric surgeries & $\begin{array}{l}\text { Total } \\
\%(n) \\
(1255)\end{array}$ & $\begin{array}{l}\text { Awdal } \\
\%(n) \\
19.1(240)\end{array}$ & $\begin{array}{l}\text { Maroodi Jeex } \\
\%(n) \\
76.0(954)\end{array}$ & $\begin{array}{l}\text { Sahil } \\
\%(n) \\
1.5(19)\end{array}$ & $\begin{array}{l}\text { Sanaag } \\
\%(n) \\
0.2(2)\end{array}$ & $\begin{array}{l}\text { Togdheer } \\
\%(n) \\
3.2(40)\end{array}$ & $p$ \\
\hline \multicolumn{8}{|l|}{ Gender } \\
\hline Male & $56.7(712)$ & $56.3(135)$ & $56.2(536)$ & $57.9(11)$ & $100.0(2)$ & $70.0(28)$ & 0.117 \\
\hline Female & $42.7(536)$ & $43.7(105)$ & $43.1(411)$ & $42.1(8)$ & $0.0(0)$ & $30.0(12)$ & \\
\hline Unknown & $0.6(7)$ & $0.0(0)$ & $0.7(7)$ & $0.0(0)$ & $0.0(0)$ & $0.0(0)$ & \\
\hline \multicolumn{8}{|l|}{ Age } \\
\hline 0-28 days & $8.8(110)$ & $2.5(6)$ & $10.7(102)$ & $0(0)$ & $0(0)$ & $5(2)$ & $<0.001$ \\
\hline $1-12$ months & $12.8(161)$ & $9.2(22)$ & $14.1(134)$ & $0(0)$ & $50(1)$ & $10(4)$ & \\
\hline $1-5$ years & $25.7(322)$ & $21.3(51)$ & $26.3(251)$ & $26.3(5)$ & $0(0)$ & $37.5(15)$ & \\
\hline$>5$ years & $52.8(662)$ & $67.1(161)$ & $49(467)$ & $73.7(14)$ & $50(1)$ & 47.5 (19) & \\
\hline \multicolumn{8}{|l|}{ Region of origin } \\
\hline In country & & & & & & & $<0.001$ \\
\hline Awdal & $7.3(92)$ & $20.0(48)$ & $4.6(44)$ & $0.0(0)$ & $0.0(0)$ & $0.0(0)$ & \\
\hline Maroodi Jeex & $55.1(692)$ & $44.2(106)$ & $61.3(585)$ & $5.3(1)$ & $0.0(0)$ & $0.0(0)$ & \\
\hline Sahil & $2.2(28)$ & $0.8(2)$ & $1.5(14)$ & $63.2(12)$ & $0.0(0)$ & $0.0(0)$ & \\
\hline Sool & $2.9(36)$ & $2.1(5)$ & $3.3(31)$ & $0.0(0)$ & $0.0(0)$ & $0.0(0)$ & \\
\hline Sanaag & $2.2(28)$ & $0.8(2)$ & $2.5(24)$ & $0.0(0)$ & $100(2)$ & $0.0(0)$ & \\
\hline Togdheer & 15.8 (198) & $10.83(26)$ & $13.21(126)$ & $31.58(6)$ & $0.0(0)$ & $100(40)$ & \\
\hline Out of country* & 14.1 (177) & $21.3(51)$ & $13.2(126)$ & $0.0(0)$ & $0.0(0)$ & $0.0(0)$ & \\
\hline Unknown & $0.3(4)$ & $0.0(0)$ & $0.4(4)$ & $0.0(0)$ & $0.0(0)$ & $0.0(0)$ & \\
\hline
\end{tabular}

*Includes: Somalia and Ethiopia

financing instruments to UHC [39], a model that may have success if implemented in Somaliland. From a provider standpoint, partnerships are growing to address the lack of surgical and anesthesia providers in Somaliland. The Safe Anesthesia for Somaliland Partnership (SANSOM) is a collaborative effort between public and private charity and national entities to train and hire anesthesia providers, in addition to providing anesthesia equipment throughout the region. In addition, the College of Surgeons of East, Central and Southern Africa (COSECSA) accredited the Edna Adan University Hospital for surgical training in the region Strategically addressing disparities in the surgical care for children through a comprehensive national health system with manpower and resources at different levels commensurate with local needs is needed and is advocated by the Optimal Resources for Children's Surgery (OReCS) document of the Global Initiative for Children's Surgery (GICS) [32]. Somaliland hospitals reported relatively stable levels of infrastructure resources such as electricity, water, and internet. The LCoGS and several countryspecific studies have identified lack of these resources as major limitations in delivery of care and cause for surgical delay [32, 36, 40]. Somaliland hospitals reported levels should be considered a marker of success and a case for feasibility of scale up. Furthermore, a comprehensive model of surgical care delivery for children, including addressing needs related to infrastructure, supplies, staffing, and systems, is needed in LMICs. Recent progress in developing National Surgical, Obstetric, and Anaesthesia Plans (NSOAPs) which are intersectoral, multi-disciplinary, and driven by local stakeholders has been pivotal in directing implementation of surgical care at all levels of health delivery systems [32, 36]. Pediatric surgical care models are different from adult models of care with regard to supplies, staff, and stakeholders and as a result, pediatric-specific models have not yet been incorporated into many of these NSOAPs.

Combining population-based burden of disease analyses with detailed studies of surgical infrastructure can help with policy guidance, particularly for healthcare systems in severely constrained resource settings. Our recent companion study in Somaliland showed a high prevalence of pediatric surgical conditions of $12 \%$, translating to over 250,000 children with surgical conditions across the country [24] . When combined with our current hospitalbased survey, it is clear that the vast majority of children do not receive any or appropriate surgical care, underscoring the need in Somaliland to scale up surgical systems. For example, tonsillectomies comprise a high proportion (almost $20 \%$ ) of surgical procedures across the country, while 
Table 2 Details of surgical procedures in children $(N=1255)$

\begin{tabular}{|c|c|c|c|c|c|c|c|}
\hline No. of pediatric surgeries & $\begin{array}{l}\text { Total } \\
\%(n) \\
(1255)\end{array}$ & $\begin{array}{l}\text { Awdal } \\
\%(n) \\
19.1(240)\end{array}$ & $\begin{array}{l}\text { Maroodi Jeex } \\
\%(n) \\
76.0(954)\end{array}$ & $\begin{array}{l}\text { Sahil } \\
\%(n) \\
1.5(19)\end{array}$ & $\begin{array}{l}\text { Sanaag } \\
\%(n) \\
0.2(2)\end{array}$ & $\begin{array}{l}\text { Togdheer } \\
\%(n) \\
3.2(40)\end{array}$ & $p$ \\
\hline \multicolumn{8}{|l|}{ Surgery provider } \\
\hline Surgeon & $95.9(1203)$ & $99.2(238)$ & $95.2(908)$ & $89.5(17)$ & $0.0(0)$ & $100.0(40)$ & 0.106 \\
\hline Other $^{\dagger}$ & $4.1(52)$ & $0.8(2)$ & $4.8(46)$ & $10.5(2)$ & $100.0(2)$ & $0.0(0)$ & \\
\hline \multicolumn{8}{|l|}{ Anesthesia provider } \\
\hline Anesthetist & $85.5(1073)$ & $99.2(238)$ & $84.9(810)$ & $21.1(4)$ & $0.0(0)$ & $52.5(21)$ & $<0.001$ \\
\hline Other $^{\dagger \dagger}$ & $14.5(182)$ & $0.8(2)$ & $15.1(144)$ & $78.9(15)$ & $100.0(2)$ & 47.5 (19) & \\
\hline \multicolumn{8}{|l|}{ Anesthesia type } \\
\hline General & $85.2(1069)$ & $96.3(231)$ & $85.6(817)$ & $15.8(3)$ & $50.0(1)$ & $42.5(17)$ & $<0.001$ \\
\hline Regional & $3.1(39)$ & $0.4(1)$ & $3.7(35)$ & $5.3(1)$ & $0.0(0)$ & $5.0(2)$ & \\
\hline Local & $11.7(147)$ & $3.3(8)$ & $10.7(102)$ & $78.9(15)$ & $50.0(1)$ & $52.5(21)$ & \\
\hline \multicolumn{8}{|l|}{ Urgency } \\
\hline Elective & $58.5(712)$ & $78.2(187)$ & $55.5(509)$ & $15.8(3)$ & $0.0(0)$ & $32.5(13)$ & $<0.001$ \\
\hline Emergency & $41.5(505)$ & $21.8(52)$ & $44.5(408)$ & $84.2(16)$ & $100(2)$ & $67.5(27)$ & \\
\hline \multicolumn{8}{|l|}{ Surgical category } \\
\hline PED & $22.9(287)$ & $17.2(41)$ & $21.0(200)$ & $73.7(14)$ & $100.0(2)$ & $75.0(30)$ & $\mathrm{n} / \mathrm{a}$ \\
\hline ENT & $19.4(243)$ & $55.0(132)$ & 11.4 (109) & $0.0(0)$ & $0.0(0)$ & $5.0(2)$ & \\
\hline ORT & 15.8 (198) & $9.6(23)$ & $17.6(168)$ & 21.0 & $0.0(0)$ & $7.5(3)$ & \\
\hline ОРТНО & $15.1(189)$ & $0.0(0)$ & 19.8 (189) & $0.0(0)$ & $0.0(0)$ & $0.0(0)$ & \\
\hline NSU & $11.3(142)$ & $2.9(7)$ & $14.1(135)$ & $0.0(0)$ & $0.0(0)$ & $0.0(0)$ & \\
\hline PSU & 8.9 (112) & 7.9 (19) & 9.7 (93) & $0.0(0)$ & $0.0(0)$ & $0.0(0)$ & \\
\hline URO & $5.8(73)$ & 6.7 (16) & $5.6(53)$ & $0.0(0)$ & $0.0(0)$ & $10.0(4)$ & \\
\hline UNKNOWN & $0.5(6)$ & $0.4(1)$ & $0.5(5)$ & $0.0(0)$ & $0.0(0)$ & $0.0(0)$ & \\
\hline OBS & $0.4(5)$ & $0.4(1)$ & $0.2(2)$ & $5.3(1)$ & $0.0(0)$ & $2.5(1)$ & \\
\hline
\end{tabular}

Surgical category key: PED general surgery; ENT otolaryngology; ORT orthopedics; OPTHO ophthalmology; NSU neurology; $P S U$ plastic surgery; $U R O$ urology; $O B S$ obstetrics

${ }^{\dagger}$ Other surgery providers include: Nurse $(0.0 \%)$, physician $(0.16 \%)$, pediatric surgeon $(0.16 \%)$, other $(0.24 \%)$, and unknown $(3.59 \%)$

${ }^{\dagger}$ Other anesthesia providers include: Anesthesiologist (12.0\%), nurse $(0.16 \%)$, clinical officer $(0.0 \%)$, other $(3.75 \%)$, unknown $(0.0 \%)$

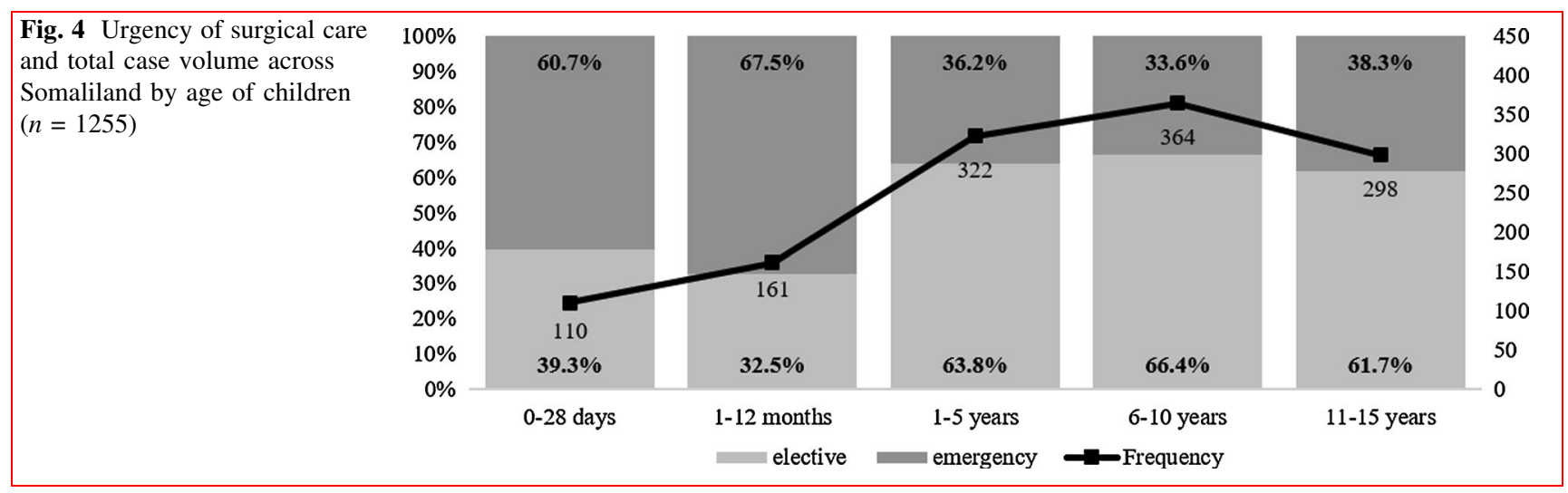

there are low rates of procedures for congenital anomalies or traumatic injuries, despite their large burden across this country and many other LMICs $[6,7,15,20,24,41-46]$. A focus on essential surgical procedures can serve to develop surgical infrastructure and capacity [36, 47]. Although such "bellwether procedures" [33] have not been defined for children and might differ among pediatric surgical subspecialties, they likely include care for conditions such as 
Table 3 Ten most common procedures overall and top three by specialty (top two were included if more than two conditions tied for third most common, top four were included if two conditions tied for third most common)

\begin{tabular}{|c|c|}
\hline Overall & $\%(n)$ \\
\hline Tonsillitis & $18.3(230)$ \\
\hline Trauma* & $11.2(141)$ \\
\hline Hydrocephalus & $7.5(94)$ \\
\hline Cataract & $6.7(84)$ \\
\hline Fracture & $6.4(80)$ \\
\hline Cleft Lip & $4.1(52)$ \\
\hline Abscess & $3.6(45)$ \\
\hline Unknown & $3.4(43)$ \\
\hline MMC & $3.1(39)$ \\
\hline Cyst/mass & $2.8(35)$ \\
\hline \multicolumn{2}{|l|}{ General surgery (PED) } \\
\hline Trauma & $19.9(57)$ \\
\hline Abscess & $15.7(45)$ \\
\hline Cyst/mass & $9.4(27)$ \\
\hline \multicolumn{2}{|l|}{ Otolaryngology $(\mathrm{ENT})^{* *}$} \\
\hline Tonsillitis & $94.7(230)$ \\
\hline Trauma & $3.7(9)$ \\
\hline \multicolumn{2}{|l|}{ Orthopedics (ORT) } \\
\hline Fracture & $40.1(79)$ \\
\hline Unknown & $16.8(33)$ \\
\hline Clubfoot & $12.7(25)$ \\
\hline \multicolumn{2}{|l|}{ Ophthalmology (OPTHO) } \\
\hline Cataract & $44.4(84)$ \\
\hline Trauma & $28.6(54)$ \\
\hline Glaucoma & $9.5(18)$ \\
\hline \multicolumn{2}{|l|}{ Neurology (NSU) } \\
\hline Hydrocephalus & $66.2(94)$ \\
\hline Myelomeningocele & $27.5(39)$ \\
\hline Encephalocele & $4.9(7)$ \\
\hline \multicolumn{2}{|l|}{ Plastic surgery (PSU) } \\
\hline Cleft Lip & $46.4(52)$ \\
\hline Contracture & $20.5(23)$ \\
\hline Cleft Palate & $14.3(16)$ \\
\hline Cleft Lip/Palate & $14.3(16)$ \\
\hline \multicolumn{2}{|l|}{ Urology (URO) } \\
\hline Circumcision & $41.1(30)$ \\
\hline Bladder stone & $17.8(13)$ \\
\hline Phimosis & $15.1(11)$ \\
\hline Anorectal malformation & $15.1(11)$ \\
\hline \multicolumn{2}{|l|}{ Obstetrics (OBS) } \\
\hline Prolonged labor & $100(5)$ \\
\hline
\end{tabular}

*Includes trauma, wounds, and snake bites

**Four other conditions had one case each, tying for third most common inguinal hernia, congenital anomalies, and traumatic injuries [32].

There are several limitations to our study, many which are common to the use of hospital-based surveys. First, although the use of a single-page hospital survey limited our ability to collect granular data on hospital infrastructure and capacity, it reduced the burden of data collection and allowed us to travel to remote hospitals and complete the survey in a timely manner. Additionally, this single-page assessment has not been validated on its own. Validation of a low-burden hospital assessment tool is an important step to quantify hospital capacity on a large scale. Secondly, little information was available in the surgical logbook records other than name, age, procedure, and name of the surgeon or physician. Therefore, we were not able to capture data on clinical outcomes, quality of care provided, or severity of the conditions prior to surgery. Additionally, we were not able to collect any information on surgical procedures performed outside of the operating theater. Further studies would need to rely on expanded data collection to enhance data quality and information, such as detailing health seeking behavior, surgical complications, costs of care, and other outcomes [48].

In summary, we found that the number of surgical procedures performed in children across Somaliland is low and insufficient for the burden of surgical disease. Surgical care is largely absent in rural regions, and the types of surgical procedures are skewed to low-burden conditions (such as tonsillitis) and not reflective of the burden of surgical conditions in the population, particularly the highburden conditions such as congenital anomalies. This study is the first of its kind to systematically assess the delivery of pediatric surgical care across Somaliland and complements our prior analysis of the burden of pediatric surgical conditions across Somaliland [24, 49].

We offer several policy recommendations to address these gaps in surgical care for children:

- A national healthcare plan, such as NSOAPs, should include strategic support for basic surgical services addressing the health needs of children.

- Implementation of a set of essential surgical procedures at district and regional hospitals is "low-hanging fruit" to increase access to surgical care, particularly in rural areas of Somaliland, in conjunction with advocacy and strong collaboration with in-country government and health officials.

- Expansion of surgical capacity, manpower, and infrastructure at all public hospitals across Somaliland is required to support a comprehensive health system for the surgical care of children. 
Table 4 Pediatric surgical procedures at 15 hospitals in Somaliland, stratified by hospital type $(N=1255)$

\begin{tabular}{|c|c|c|c|c|}
\hline & Private not-for-profit $\%(n)$ & Private for-profit $\%(n)$ & Public Government $\%(n)$ & $p$ \\
\hline Total & $51.5(647)$ & $28.3(355)$ & $20.2(253) \dagger$ & \\
\hline \multicolumn{5}{|l|}{ Gender } \\
\hline Male & $56.54(363)$ & $54.96(194)$ & $61.26(155)$ & 0.312 \\
\hline Female & $43.46(279)$ & $45.04(159)$ & $38.74(98)$ & \\
\hline \multicolumn{5}{|l|}{ Age } \\
\hline 0-28 days & $5.9(38)$ & $17.2(61)$ & $4.4(11)$ & $<0.001$ \\
\hline $1-12$ months & $19.5(126)$ & $6.2(22)$ & $5.1(13)$ & \\
\hline $1-5$ years & 27.7 (179) & $21.4(76)$ & $26.5(67)$ & \\
\hline$>5$ years & $47(304)$ & $55.2(196)$ & $64(162)$ & \\
\hline \multicolumn{5}{|l|}{ Urgency } \\
\hline Elective & $61.3(392)$ & $72.8(236)$ & $32.0(81)$ & $<.0001$ \\
\hline Emergency & $38.8(248)$ & $27.2(88)$ & $68.0(172)$ & \\
\hline Surgical category & & & & $<0.001$ \\
\hline PED & $5.3(34)$ & $27.3(97)$ & $61.7(156)$ & \\
\hline ENT & $15.4(100)$ & $37.2(132)$ & $4.4(11)$ & \\
\hline ORT & $11.0(71)$ & $14.4(51)$ & $30.0(76)$ & \\
\hline OPTHO & $29.2(189)$ & $0.0(0)$ & $0.0(0)$ & \\
\hline NSU & $20.9(135)$ & $2.0(7)$ & $0.0(0)$ & \\
\hline PSU & $14.4(93)$ & $5.4(19)$ & $0.0(0)$ & \\
\hline URO & $3.1(20)$ & $13.0(46)$ & $2.8(7)$ & \\
\hline UNKNOWN & $0.8(5)$ & $0.3(1)$ & $0.0(0)$ & \\
\hline OBS & $0.0(0)$ & $0.6(2)$ & $1.2(3)$ & \\
\hline Top 5 conditions & & & & $<0.001$ \\
\hline Tonsillitis & $14.8(96)$ & $36.9(131)$ & $1.2(3)$ & \\
\hline Trauma* & $11.3(73)$ & $1.7(6)$ & $24.5(62)$ & \\
\hline Hydrocephalus & $14.2(92)$ & $0.6(2)$ & $0.0(0)$ & \\
\hline Cataract & $13.0(84)$ & $0.0(0)$ & $0.0(0)$ & \\
\hline Fracture & $2.8(18)$ & $5.1(18)$ & $17.8(45)$ & \\
\hline Region of Origin & & & & $<0.001$ \\
\hline \multicolumn{5}{|l|}{ In country } \\
\hline Awdal & $61.8(400)$ & $47.3(168)$ & $49.0(124)$ & \\
\hline Maroodi Jeex & $13.9(90)$ & $13.0(46)$ & $24.5(62)$ & \\
\hline Sahil & $4.3(28)$ & $13.2(47)$ & $6.7(17)$ & \\
\hline Sool & $3.4(22)$ & $2.3(8)$ & $2.4(6)$ & \\
\hline Sanaag & $1.7(11)$ & $0.6(2)$ & $5.9(15)$ & \\
\hline Togdheer & $2.3(15)$ & $1.7(6)$ & $2.8(7)$ & \\
\hline Out of country** & $12.1(78)$ & $22.0(78)$ & $8.3(21)$ & \\
\hline Unknown & $0.5(3)$ & $0.0(0)$ & $0.4(1)$ & \\
\hline
\end{tabular}

Surgical category code: PED general surgery; ENT otolaryngology; ORT orthopedics; OPTHO ophthalmology; NSU neurology; PSU plastic surgery; $U R O$ urology; $O B S$ obstetrics

${ }^{\dagger}$ National hospital $(14.7 \%)$ and regional/district hospitals (5.4\%)

*Includes: trauma, wounds, and snake bites

***ncludes: Somalia and Ethiopia

Acknowledgements We want to thank the Global Initiative for Children's Surgery (GICS) for its support of this work. GICS (www. globalchildrenssurgery.org) is a network of children's surgical and anesthesia providers from low-, middle-, and high-income countries collaborating for the purpose of improving the quality of surgical care for children globally. 


\section{References}

1. Abdullah F, Troedsson H, Cherian M (2011) The World Health Organization Program for emergency surgical, obstetric, and anesthetic care: from Mongolia to the future. Arch Surg 146:620-623. https://doi.org/10.1001/archsurg.2011.84

2. Okoroh JS, Chia V, Oliver EA et al (2015) Strengthening health systems of developing countries: inclusion of surgery in universal health coverage. World J Surg Lupsingen 39:1867-1874. https:// doi.org/10.1007/s00268-015-3031-7

3. Strengthening emergency and essential surgical care and anaesthesia in the context of universal health coverage (2015). https:// www.who.int/surgery/wha-eb/en/. Accessed 30 Sept 2018

4. Bickler SW, Rode H (2002) Surgical services for children in developing countries. Bull World Health Organ 80:829-835

5. Bickler SW, Telfer ML, Sanno-Duanda B (2003) Need for paediatric surgery care in an urban area of the Gambia. Trop Doct 33:91-94. https://doi.org/10.1177/004947550303300212

6. Butler EK, Tran TM, Fuller AT et al (2016) Quantifying the pediatric surgical need in Uganda: results of a nationwide crosssectional, household survey. Pediatr Surg Int 32:1075-1085. https://doi.org/10.1007/s00383-016-3957-3

7. Butler EK, Tran TM, Nagarajan N et al (2017) Epidemiology of pediatric surgical needs in low-income countries. PLoS ONE 12:e0170968. https://doi.org/10.1371/journal.pone.0170968

8. Debas HT, Gosselin R, McCord C et al (2006) Surgery. In: Jamison DT, Breman JG, Measham AR, Alleyne G, Claeson M, Evans DB, Jha P, Mills A, Musgrove P (eds) Disease control priorities in developing countries. World Bank, Washington, DC

9. Ozgediz D, Poenaru D (2012) The burden of pediatric surgical conditions in low and middle income countries: a call to action. J Pediatr Surg 47:2305-2311. https://doi.org/10.1016/j.jpedsurg. 2012.09.030

10. Bickler SW, Sanno-Duanda B (2000) Epidemiology of paediatric surgical admissions to a government referral hospital in the Gambia. Bull World Health Organ 78:1330-1336

11. Sitkin NA, Farmer DL (2016) Congenital anomalies in the context of global surgery. Semin Pediatr Surg 25:15-18. https://doi. org/10.1053/j.sempedsurg.2015.09.004

12. Smith ER, Vissoci JRN, Rocha TAH et al (2017) Geospatial analysis of unmet pediatric surgical need in Uganda. J Pediatr Surg 52:1691-1698. https://doi.org/10.1016/j.jpedsurg.2017.03. 045

13. Kushner AL, Groen RS, Kamara TB et al (2012) Assessment of pediatric surgery capacity at government hospitals in Sierra Leone. World J Surg 36:2554-2558. https://doi.org/10.1007/ s00268-012-1737-3

14. Kendig CE, Samuel JC, Varela C et al (2014) Pediatric surgical care in Lilongwe, Malawi: outcomes and opportunities for improvement. J Trop Pediatr 60:352-357. https://doi.org/10. 1093/tropej/fmu026

15. Petroze RT, Calland JF, Niyonkuru F et al (2014) Estimating pediatric surgical need in developing countries: a household survey in Rwanda. J Pediatr Surg 49:1092-1098. https://doi.org/ 10.1016/j.jpedsurg.2014.01.059

16. Contini S, Taqdeer A, Cherian M et al (2010) Emergency and essential surgical services in Afghanistan: still a missing challenge. World J Surg 34:473-479. https://doi.org/10.1007/s00268010-0406-7

17. Walker IA, Obua AD, Mouton F et al (2010) Paediatric surgery and anaesthesia in south-western Uganda: a cross-sectional survey. Bull World Health Organ 88:897-906. https://doi.org/10. 2471/BLT.10.076703

18. Fuller AT, Haglund MM, Lim S et al (2016) Pediatric neurosurgical outcomes following a neurosurgery health system intervention at Mulago National Referral Hospital in Uganda. World Neurosurg 95:309-314. https://doi.org/10.1016/j.wneu. 2016.07.090

19. Elkheir N, Sharma A, Cherian M et al (2014) A cross-sectional survey of essential surgical capacity in Somalia. BMJ Open 4:e004360. https://doi.org/10.1136/bmjopen-2013-004360

20. Bolkan HA, Von Schreeb J, Samai MM et al (2015) Met and unmet needs for surgery in Sierra Leone: a comprehensive, retrospective, countrywide survey from all health care facilities performing operations in 2012. Surgery 157:992-1001. https:// doi.org/10.1016/j.surg.2014.12.028

21. Shrime MG, Sleemi A, Ravilla TD (2015) Specialized surgical platforms. In: Debas HT, Donkor P, Gawande A, Jamison DT, Kruk ME, Mock CN (eds) Essential surgery: disease control priorities, vol 1, 3rd edn. The International Bank for Reconstruction and Development/The World Bank, Washington, DC

22. Sheik Ali S, Jaffry Z, Cherian MN et al (2017) Surgical human resources according to types of health care facility: an assessment in low- and middle-income countries. World J Surg 41:2667-2673. https://doi.org/10.1007/s00268-017-4078-4

23. New World Bank GDP and poverty estimates for Somaliland. World Bank. https://www.worldbank.org/en/news/press-release/ 2014/01/29/new-world-bank-gdp-and-poverty-estimates-forsomaliland. Accessed 16 Nov 2016

24. Concepcion T, Mohamed M, Dahir S et al (2019) Prevalence of pediatric surgical conditions across Somaliland. JAMA Netw Open 2:e186857. https://doi.org/10.1001/jamanetworkopen.2018. 6857

25. Somaliland Profile (2017) BBC News. https://www.bbc.com/ news/world-africa-14115069. Accessed 26 Jan 2018

26. World Bank (2015) SOMALILAND: poverty profile and overview of living conditions

27. Under-Five Mortality. UNICEF DATA. https://data.unicef.org/ topic/child-survival/under-five-mortality/. Accessed 15 June 2018

28. Neonatal Mortality. UNICEF DATA. https://data.unicef.org/ topic/child-survival/neonatal-mortality/. Accessed 15 June 2018

29. World Bank (2013) Africa Development Indicators 2012/13. World Bank, Washington, DC

30. Somaliland Ministry of Health (2011) National Health Policy. Ministry of Health

31. WHO-PGSSC Surgical Assessment Tool (SAT) Hospital walkthrough. Implementation of the Lancet Commission on Global Surgery. TOOLS. https://www.lancetglobalsurgery.org/imple mentation-tools. Accessed 28 Jan 2018

32. Goodman LF, St-Louis E, Yousef Y et al (2018) The global initiative for children's surgery: optimal resources for improving care. Eur J Pediatr Surg Off J Austrian Assoc Pediatr Surg Al Z Kinderchir 28:51-59. https://doi.org/10.1055/s-0037-1604399

33. O'Neill KM, Greenberg SLM, Cherian M et al (2016) Bellwether procedures for monitoring and planning essential surgical care in low- and middle-income countries: caesarean delivery, laparotomy, and treatment of open fractures. World J Surg 40:2611-2619. https://doi.org/10.1007/s00268-016-3614-y

34. Hipgrave DB, Hort K (2014) Dual practice by doctors working in South and East Asia: a review of its origins, scope and impact, and the options for regulation. Health Policy Plan 29:703-716. https://doi.org/10.1093/heapol/czt053

35. Paina L, Bennett S, Ssengooba F et al (2014) Advancing the application of systems thinking in health: exploring dual practice and its management in Kampala. Uganda. Health Res Policy Syst 12:41. https://doi.org/10.1186/1478-4505-12-41

36. Meara JG, Leather AJ, Hagander L et al (2015) Global Surgery 2030: evidence and solutions for achieving health, welfare, and economic development. The Lancet 386:569-624 
37. Devi S (2015) Slowly and steadily, Somaliland builds its health system. The Lancet 385:2139-2140. https://doi.org/10.1016/ S0140-6736(15)61009-1

38. Smith ER, Concepcion TL, Niemeier KJ et al (2018) Is global pediatric surgery a good investment? World J Surg 225:32. https://doi.org/10.1007/s00268-018-4867-4

39. Cotlear D, Rosemberg N (2018) Going universal in Africa: how 46 African countries reformed user fees and implemented health care priorities. The World Bank 2018. https://documents.world bank.org/curated/en/712041516179885313/Going-universalin-Africa-how-46-African-countries-reformed-user-fees-andimplemented-health-care-priorities. Accessed 22 Aug 2018

40. Kingham TP, Kamara TB, Cherian MN et al (1960) Quantifying surgical capacity in Sierra Leone: a guide for improving surgical care. Arch Surg Chic Ill 2009(144):122-127. https://doi.org/10. 1001/archsurg.2008.540 (discussion 128)

41. GBD 2015 Child Mortality Collaborators (2016) Global, regional, national, and selected subnational levels of stillbirths, neonatal, infant, and under-5 mortality, 1980-2015: a systematic analysis for the Global Burden of Disease Study 2015. Lancet Lond Engl 388:1725-1774. https://doi.org/10.1016/S01406736(16)31575-6

42. Gupta S, Shrestha S, Ranjit A et al (2015) Conditions, preventable deaths, procedures and validation of a countrywide survey of surgical care in Nepal. Br J Surg 102:700-707. https:// doi.org/10.1002/bjs. 9807

43. Saxton AT, Poenaru D, Ozgediz D et al (2016) Economic analysis of children's surgical care in low- and middle-income countries: a systematic review and analysis. PLoS ONE 11:e0165480. https://doi.org/10.1371/journal.pone.0165480
44. Abdelgadir J, Punchak M, Smith ER et al (2018) Pediatric traumatic brain injury at Mbarara Regional Referral Hospital, Uganda. J Clin Neurosci Off $\mathbf{J}$ Neurosurg Soc Australas 47:79-83. https://doi.org/10.1016/j.jocn.2017.10.004

45. Smith ER, van de Water BJ, Martin A et al (2018) Availability of post-hospital services supporting community reintegration for children with identified surgical need in Uganda. BMC Health Serv Res 18:727. https://doi.org/10.1186/s12913-018-3510-2

46. Bearden A, Fuller AT, Butler EK et al (2018) Rural and urban differences in treatment status among children with surgical conditions in Uganda. PLoS ONE. https://doi.org/10.1371/jour nal.pone. 0205132

47. Mock CN, Donkor P, Gawande A et al (2015) Essential surgery: key messages from Disease Control Priorities, 3rd edition. The Lancet 385:2209-2219. https://doi.org/10.1016/S01406736(15)60091-5

48. Abdelgadir J, Smith ER, Punchak M et al (2017) Epidemiology and characteristics of neurosurgical conditions at Mbarara regional referral hospital. World Neurosurg 102:526-532. https:// doi.org/10.1016/j.wneu.2017.03.019

49. Zafar SN, Canner JK, Nagarajan N et al (2018) Road traffic injuries: cross-sectional cluster randomized countrywide population data from 4 low-income countries. Int J Surg Lond Engl 52:237-242. https://doi.org/10.1016/j.ijsu.2018.02.034

Publisher's Note Springer Nature remains neutral with regard to jurisdictional claims in published maps and institutional affiliations. 